\title{
Communication between general practitioners and consultants: what should their letters contain?
}

\author{
John Newton, Martin Eccles, Allen Hutchinson
}

\begin{abstract}
Objective-To canvass the views of all general practitioners and consultants working in Newcastle upon Tyne on the content of referral letters and replies, the feasibility of standardising certain aspects of referral letters, and the use of communications data for audit purposes.

Design-A postal questionnaire was sent to all general practitioners and consultants in Newcastle upon Tyne in May 1991. Questions were asked about the clinical and administrative content of letters, the utility of standard categories to state the reason for referral, the idea of using letters for feedback purposes, and communications as a potential topic for professionally led audit.
\end{abstract}

Setting-Area served by Newcastle upon Tyne Family Health Services Authority and District Health Authority.

Results-Replies were received from 274 (77\%) doctors (115 general practitioners and 159 consultants). A majority $(225 ; 82 \%)$ were in favour of items defined as "always important" forming a minimum requirement for referral letters and for consultants' replies. Using standardised categories to state the reason for referral was not endorsed: $102(89 \%)$ general practitioners and $132(83 \%)$ consultants preferred referrers to use their own words. Using referral communications to provide feedback was less popular with consultants $(54 ; 34 \%)$ than general practitioners $(72 ; 63 \%)$. Finally, a majority of doctors $(179 ; 65 \%)$ were in favour of using written communications as a topic for professionally led audit.

Conclusions-A high degree of consensus exists among clinicians about the content of referral communications. Although doctors may still reject the concept of standardised communications, they have unambiguously endorsed a standard for communication that they can aspire to, and they are prepared to use it as a yardstick for their actual performance.

Centre for Health Services Research, University of Newcastle upon Tyne, Newcastle upon Tyne NE2 4AA

John Newton, MSC, visiting fellow

Martin Eccles, MD, clinical research associate

Allen Hutchinson, FRCGP, programme director

Correspondence to: Mr Newton.

BMF 1992;304:821-4

\section{Introduction}

In the referral process, letters are the standardand typically the sole-method of communicating information between general practitioners and hospital specialists. ${ }^{1}$ Letters provide a flexible medium because their form and content can be adapted to cover referrals ranging from straightforward technical problems to complex cases in which extensive details need to be communicated in both directions. Moreover, there is a recognition that referral letters and replies can function as a means of education for both parties. Since patient care hinges at least in part on how well both general and case specific knowledge and expectations are conveyed from one clinician to another it is important that this medium works as efficiently as possible. There is evidence, however, that clinicians are often dissatisfied with this aspect of their practice..$^{2-4}$ Issues relating to the content of referral letters and replies seem to be at the forefront of such concerns.

More recently, managers and administrators have emphasised an additional imperative for addressing the issue of referral communication. Purchasing and contracting for services necessarily requires a level of detail not previously acknowledged in terms of demographic and classificatory data. Studies by the Department of Health have specified these minimum data sets ${ }^{5}$ and the ill fated standardised referral letter was a first attempt at collecting these structured data.

The literature on referral communications consists of two types of contribution. In the first category are what might be termed personal views. Here doctors set out what they think a referral letter or reply should contain. Most commentators have concentrated on the general practitioner's referral letter, but there is a low degree of consensus on the desired features. Fletcher, for example, listed reason for referral, outline of history, treatments given, and sociopsychological background as important to include ${ }^{6}$ while TudorHart and Marinker produced a checklist of seven items, including a clear identification of the patient, a statement about the patient's present problem, and a statement of what the patient has been told about their condition and about the reason for referral. ${ }^{7}$ Further discrepancies can be found between these two contributions and others. Some authors think that consensus will emerge in discussion and recommend that communications protocols should be agreed between general practitioners and "a variety of specialists."

The second type of communications study is based on the collection of empirical material in the form of doctors' views elicited by questioning or by analysing the content of actual letters. Young et al, for example, asked 25 general practitioners to rate the importance of 11 items of information for inclusion in consultants' letters. ${ }^{9} \mathrm{~A}$ high degree of consensus on "factual" items was revealed, with less agreement about "comment" items. A similar methodology was used in a study of referrals to child psychiatry. ${ }^{10}$ Opinions about content were compared with actual letters and it was concluded that the requirements of both parties were being met only to a limited extent. Scaffardi also found similar types of deficiencies in communications between general practitioners and physiotherapists. ${ }^{.1}$

A common approach, therefore, has been to seek the views of doctors about the relative importance of several content items before assessing how well existing communications match up to these "information needs." Unfortunately, most of the studies have been conducted within one specialty, often psychiatry. More information is needed from a wider spectrum of doctors on these content matters and on the issues concerning standard setting raised by Marinker $\mathrm{et} \mathrm{al} .^{8}$

The present study was therefore designed to canvass the views of all general practitioners and consultants 
working in Newcastle upon Tyne, seeking their opinion on the relative importance of a range of information and data items that might be included in professional communications. Additionally, the study aimed to determine whether letter communications should be used to influence clinical and referral practice.

\section{Method}

A postal questionnaire seeking views about the content of general practitioners' referral letters and consultants' first replies to them was sent to all the 157 general practitioners in contract with Newcastle Family Health Services Authority and 200 of the consultants working in Newcastle, a teaching authority that includes three large acute hospitals and a major mental health unit. Two of the units were NHS trusts. Consultant anaesthetists and consultant dental surgeons were excluded on the grounds that they did not routinely receive general practitioner referrals. A reminder was sent to non-respondents at 14 days.

The doctors were asked for their views within five broad areas: the clinical content of general practitioners' letters to consultants; the administrative content of general practitioners' letters to consultants; the clinical content of consultants' replies to general practitioners; the usefulness and potential content of

\section{List of items in the questionnaire}

Clinical content of general practitioner's letter:

- Initial sentence stating reason for referral

- Outline of the history or statement of the problem

- Important medical history

- Findings on examination

- Findings on investigation

- Current medication

- Sociopsychological matters

- Known allergies

- Whether or how the patient was involved in the referral decision

- What the patient or relative has been told

- What the patient or relative expects from the referral

- What the general practitioner expects from the referral

- Whether new referral or re-referral

Administrative content of general practitioner's letter

- General practitioner's name, address, and telephone number

- Consultant's name, department, and address

- Patient's name, address, telephone number, post code, date of birth, sex, NHS number

- Date on referral letter

Clinical content of consultant's reply:

- Summary of the history

- Findings on examination

- Findings on investigation

- Appraisal of problem (including diagnosis where applicable)

- Management plan

- What the patient or relative has been told

- Time to follow up appointment

- Who saw the patient

\section{Potential items to be included in feedback}

Feedback from consultants to general practitioners:

- View on appropriateness of referral

- View on whether the consultant's referral expectations were met

- View on general usefulness of the letter

- Information about the problem or condition referred

- View on quality of the general practitioner's "work up"

Feedback from general practitioners to consultants:

- View on appropriateness of the consultant's reply

- View on general usefulness of the letter

- View on whether the general practitioner's referral expectations were met

- Whether the letter provided specific information that the general practitioners had requested

- View on patient's experiences

feedback from consultants to general practitioners and vice versa; and the content of referral letters as a topic for professionally led audit.

Within the first three areas the respondents were asked to rate the items (box) on a four point scale from "always important" to "unimportant." The items were chosen from those rated as important by general practitioners who had been interviewed in a pilot study and from previous published work on the content of referral letters. ${ }^{67910}$ For the two clinical areas they were also asked if those items rated as "always important" should become a minimum requirement for the respective letters. Statistical analysis used the $\chi^{2}$ test on a $2 \times 2$ table for consultants and general practitioners. For the purpose of the analysis the responses of "always important" and "usually important" were combined and "sometimes important" and "never important" were combined.

For views about feedback the doctors were asked whether they would agree with the consultant offering feedback to the general practitioner on the "worth" of the referral and the general practitioner offering feedback to the consultant. Respondents who did not disagree with these ideas were asked to indicate which of the items shown in the box they thought should be included in feedback.

Doctors were asked whether they would prefer to use their own words or a set of standard categories when stating the reason for referral. They were also asked for their views about using written communication between general practitioners and consultants as a subject for medical audit.

\section{Results}

Replies were received from 115 (73\%) general practitioners and $159(80 \%)$ consultants. Initially the consultants were categorised as either physicians (102) or surgeons (57) and responses were analysed by specialty, but as they differed on only four items (table I), for the rest of the analysis consultants were treated as a single group. Tables II-IV show the percentages of respondents rating items as always or usually important for the clinical items in general practitioners' letters to consultants (table II), for the administrative items in general practitioners' letters to consultants (table III), and for the clinical items in consultants' replies (table IV). 
A total of $89(77 \%)$ general practitioners and 127 $(88 \%)$ consultants were in favour or strongly in favour of the clinical items in the general practitioner's letter (table II) that they had rated as "always important" forming a minimum requirement for every letter. The corresponding figures for the clinical items in a consultant's reply (table IV) were $91(79 \%)$ general practitioners and $35(85 \%)$ consultants. The reason for referral was preferred to be in the general practitioner's own words, rather than obtained by a standard set of categories, by $102(89 \%)$ general practitioners and 132 $(83 \%)$ consultants. A total of $72(63 \%)$ general practitioners thought that in all or most cases the consultant's reply to a referral letter provided the opportunity for a consultant to give feedback on the "worth" of the referral. However, only $54(34 \%)$ consultants agreed with this. A further $32(28 \%)$ general practitioners and $75(47 \%)$ consultants were undecided whether feedback was appropriate. The respondents in favour of or undecided about such feedback were asked what such feedback should consist of (table V).

In all, $94(82 \%)$ general practitioners and $126(79 \%)$ consultants thought that the process of offering feedback should be part of a dialogue, with general

TABLE I - Items within letters on which physicians and surgeons placed differing importance. Values are numbers (percentage) of doctors rating item always or usually important

\begin{tabular}{lccc}
\hline Item & $\begin{array}{c}\text { Physicians } \\
(\mathbf{n}=102)\end{array}$ & $\begin{array}{c}\text { Surgeons } \\
(\mathbf{n}=57)\end{array}$ & $\mathrm{p}$ Value \\
\hline $\begin{array}{l}\text { In general practitioner's letter: } \\
\text { Outline of history or statement of } \\
\text { problem }\end{array}$ & $99(97)$ & $50(88)$ & $<0.05$ \\
$\begin{array}{l}\text { Sociopsychological matters } \\
\text { In consultant's reply: }\end{array}$ & $64(63)$ & $19(33)$ & $<0.001$ \\
$\quad \begin{array}{l}\text { Time to follow up } \\
\text { Indication of who saw patient }\end{array}$ & $92(90)$ & $43(75)$ & $<0.05$ \\
\hline
\end{tabular}

TABLE II-Number (percentage) of general practitioners and consultants rating clinical items in general practitioner's referral letter to consultant as always or usually important

\begin{tabular}{|c|c|c|}
\hline Items in letter & $\begin{array}{c}\text { General } \\
\text { practitioners } \\
(\mathrm{n}=115)\end{array}$ & $\begin{array}{c}\text { Consultants } \\
(\mathrm{n}=159)\end{array}$ \\
\hline Outline of history or statement of the problem & $115(100)$ & $149(94)^{\star}$ \\
\hline Current medication & $110(96)$ & $146(92)$ \\
\hline Initial sentence stating reason for referral & $104(90)$ & $146(92)$ \\
\hline Important medical history & $104(90)$ & $138(87)$ \\
\hline $\begin{array}{l}\text { What the general practitioner expects from the } \\
\text { referral }\end{array}$ & $101(88)$ & $127(80)$ \\
\hline Findings on examination & $99(86)$ & $126(79)$ \\
\hline Findings on investigation & $91(79)$ & $116(73)$ \\
\hline Whether new referral or re-referral & $87(76)$ & $121(76)$ \\
\hline Known allergies & $85(74)$ & $97(61)^{\star}$ \\
\hline Sociopsychological matters & $49(43)$ & $83(52)$ \\
\hline $\begin{array}{l}\text { What the patient or relative expects from the } \\
\text { referral }\end{array}$ & $49(43)$ & $87(55)$ \\
\hline What the patient or relative has been told & $39(34)$ & $86(54)^{\star \star}$ \\
\hline $\begin{array}{l}\text { Whether or how the patient was involved in the } \\
\text { referral decision }\end{array}$ & $33(29)$ & $59(37)$ \\
\hline
\end{tabular}

TABLE III-Number (percentage) of general practitioners and consultants rating administrative items in general practitioner's referral letter to consultant as always or usually important

\begin{tabular}{lcc}
\hline & $\begin{array}{c}\text { General } \\
\text { practitioners } \\
(\mathbf{n}=115)\end{array}$ & $\begin{array}{c}\text { Consultants } \\
(\mathbf{n}=159)\end{array}$ \\
\hline Items in letter & $115(100)$ & $159(100)$ \\
\hline Patient's name & $115(100)$ & $154(97)$ \\
Patient's address & $115(100)$ & $154(97)$ \\
Patient's date of birth & $115(100)$ & $148(93)^{\star \star}$ \\
Consultant's department & $114(99)$ & $159(100)$ \\
General practitioner's name & $114(99)$ & $153(96)$ \\
General practitioner's address & $114(99)$ & $132(83)^{\star \star \star}$ \\
Consultant's address & $114(99)$ & $149(94)$ \\
The date on referral letter & $108(94)$ & $135(85)^{\star}$ \\
Patient's sex & $107(93)$ & $146(92)$ \\
Consultant's name & $105(91)$ & $135(85)$ \\
General practitioner's telephone number & $90(78)$ & $135(85)$ \\
Patient's post code & $79(69)$ & $138(87)^{\star \star \star}$ \\
Patient's telephone number & $44(38)$ & $75(47)$ \\
Patient's NHS number & & \\
\hline${ }^{\star} \mathbf{p}<0 \cdot 05 ; \star \star \mathrm{p}<0 \cdot 01 ;{ }^{\star \star \star \star}$ & & \\
& &
\end{tabular}

TABLE IV - Number (percentage) of consultants and general practitioners rating clinical items in consultant's reply to general practitioner's referral letter as always or usually important

\begin{tabular}{lrr}
\hline & $\begin{array}{c}\text { Consultants } \\
(\mathbf{n}=159)\end{array}$ & $\begin{array}{c}\text { General } \\
\text { practitioners } \\
(\mathbf{n}=115)\end{array}$ \\
\hline Items in letter & & \\
Appraisal of problem (including diagnosis where & $157(99)$ & $113(98)$ \\
$\quad$ applicable) & $154(97)$ & $114(99)$ \\
Management plan & $146(92)$ & $102(89)$ \\
Findings on examination & $145(91)$ & $98(85)$ \\
Who saw the patient & $137(86)$ & $105(91)$ \\
What the patient or relative has been told & $135(85)$ & $105(91)$ \\
Findings on investigation & $135(85)$ & $105(91)$ \\
Time to follow up appointment & $126(79)$ & $79(69)$ \\
Summary of history & &
\end{tabular}

TABLE V - Views on the content of feedback from consultants to genera practitioners about the "worth" of referral letters. (Figures are for those who agreed with or were undecided about the idea of such feedback)

\begin{tabular}{|c|c|c|}
\hline Content of feedback & $\begin{array}{c}\text { Consultants } \\
(\mathrm{n}=129)\end{array}$ & $\begin{array}{c}\text { General } \\
\text { practitioners } \\
(\mathrm{n}=104)\end{array}$ \\
\hline Information about problem or condition referred & $98(76)$ & $84(81)$ \\
\hline View on appropriateness of referral & $49(38)$ & $52(50)$ \\
\hline View on general usefulness of letter & $27(21)$ & $40(38)^{\star \star}$ \\
\hline $\begin{array}{l}\text { View on whether consultant's referral } \\
\text { expectations were met }\end{array}$ & $15(12)$ & $29(28)^{\star \star}$ \\
\hline View on quality of "work up" & $13(10)$ & $31(30)^{\star \star}$ \\
\hline
\end{tabular}

$\star \star \mathrm{p}<0 \cdot 01$

TABLE VI-Views on content of feedback from general practitioners to consultants about consultants' replies to referral letters. (Figures are for those who agreed with the idea of such feedback)

\begin{tabular}{lcc}
\hline Items & $\begin{array}{c}\text { Consultants } \\
(\mathbf{n}=122)\end{array}$ & $\begin{array}{c}\text { General } \\
\text { practitioners } \\
(\mathbf{n}=92)\end{array}$ \\
\hline $\begin{array}{l}\text { Whether letter provided specific information } \\
\text { requested by general practitioner }\end{array}$ & $71(58)$ & $58(63)$ \\
$\begin{array}{l}\text { View on whether general practitioner's referral } \\
\quad \text { expectations were met }\end{array}$ & $71(58)$ & $54(59)$ \\
View on patient's experiences & $56(46)$ & $41(45)$ \\
View on general usefulness of letter & $45(37)$ & $40(43)$ \\
View on appropriateness of reply & $35(29)$ & $34(37)$
\end{tabular}

practitioners also offering feedback to consultants. Those in favour of such a dialogue were asked what such a feedback should consist of (table VI).

Finally, in response to being asked their views on using written communication between general practitioners and consultants as a subject for professionally led audit, $74(64 \%)$ general practitioners were in favour or strongly in favour, $31(27 \%)$ were undecided, and $10(9 \%)$ were against or strongly against this. The corresponding figures for consultants were $105(66 \%)$, $35(22 \%)$, and $19(12 \%)$.

\section{Discussion}

This survey was carried out at a time of great change in the health service. Two of the four hospital units in Newcastle had been granted trust status two months before fieldwork began, and questionnaires were mailed two weeks after the NHS standard referral letter had been withdrawn in the face of critical responses from the profession. Both of these factors may have highlighted the salience of the issues to respondents, whose overall response rate was $77 \%$.

A high degree of consensus exists among clinicians in Newcastle about the clinical and administrative content of referral letters and replies. For general practitioner referral letters $75 \%$ of respondents regarded eight items as "always" or "usually" important to include, and only one item ("What the patient or relative has been told") shows a significant difference between general practitioners and consultants at the $1 \%$ level. Additionally, the two groups seem to endorse most items equally strongly; we did not, however, ask doctors to rank the items in order of importance. 
A similarly high, if not higher, degree of importance is attached to the administrative items listed in table III. This result, however, must be interpreted in the context of the newly instituted minimum data set for referral documentation. Many of our respondents, we suspect, were replying to what they regarded as a fait accompli. Even so, general practitioners and consultants varied a little in their emphasis, with consultants, for example, regarding the patient's telephone number as a more important datum than the general practitioners did. Perhaps this reflects the probability that it will be the consultant who is more likely to contact the patient once the referral process has begun.

For the consultant's reply we proposed fewer items (eight as against 13 for the general practitioner's letter) and this may have influenced the tendency to see more matters as "always" for "usually" important to include. Once again, however, the patterns of responses were remarkably similar and there were no significant differences between the two groups of clinicians.

Doctors gave less endorsement to the idea of using referral communications as a vehicle for feedback about the consultant's views on the "worth" of the referral or the general practitioner's views on the consultant's reply. General practitioners, however, seemed more prepared to receive feedback than consultants seemed prepared to give it. The minority agreeing with the idea of feedback wanted it restricted to factual information about the problem or case referred. It seems clear that although referral letters and replies may occasionally and incidentally be of educational value there is some way to go before this medium could be considered appropriate to perform this function on a regular or routine basis, let alone accommodate an extension of its functions into more evaluative territory.

A more practical and less threatening approach to improving the quality of service suggested by this study lies in the responses to our questions about auditing referral communications. The items listed in tables II-IV represent normative ideal standards and the responses suggest that the majority of doctors endorse their content. Furthermore, the majority of both general practitioners and consultants were in favour of the items most frequently rated "always" or "usually" important becoming a minimum requirement for both general practitioners' referral letters and consultants' replies. This would seem to confirm the suggestion made by Marinker et al that referral communications should form the basis of the development of protocols among groups drawn from all sections of the medical profession. ${ }^{8}$ Indeed, two thirds of our sample was in favour of using letters as a subject for professionally led audit.

There are opportunities in these results for both managers and clinicians. Although the form of the standard referral letter was rejected (not least on confidentiality grounds), doctors clearly recognise the value of administrative data, which are also necessary for monitoring contracts and referrals. Hence, it should be possible to come to some agreed minimum data set, even though it is unlikely that this would include rigid categories of reasons for referral. Otherwise, doctors from this survey have endorsed a standard for communication which they can aspire to. In practice it is likely that this will be in the form of an "optimum" rather than an "ideal" standard. Relatively little resource would be required to undertake a regular audit by general practitioners and consultants of the extent to which they each achieve and maintain their stated preferences in practice.

We thank Pauline Potts for her assistance in data handling; Nick Steen for his statistical advice; and Newcastle Family Health Services Authority for funding the study. Many doctors spent time in completing the questionnaire and we are grateful to them. Finally, we thank Sylvia Hudson, who provided secretarial and administrative support to the project.

1 Westerman RF, Hull FM, Bezemer PD, Gort G. A study of communication between general practitioners and specialists. $\mathrm{Br} \mathcal{F}$ Gen Practice 1990;40: 445-9.

2 Doleman F. Improving communications between general practitioners and specialists. Family Practice 1987;4:176-82.

3 Leonard I, Babbs C, Creed F. Psychiatric referrals within the hospital-the communication process. $\mathcal{F} R$ Soc Med 1990;83:241-4.

Roland MO, Porter RW, Matthews JG, Redden JF, Simmonds GW, Bewley B. Improving care a study of orthopaedic outpatient referrals. $B M$ B. Improving

5 Department of Health. Framework for information systems. Report of the Project 34 Working Group. London: HMSO, 1990. (Annexe 10.)

6 Fletcher CM. Communication in medicine. London: Nuffield Provincial Hospitals Trust, 1972.

7 Hart JT, Marinker M. An exchange of letters. London: MSD Foundation, 1985 Marinker M, Wilkin D, Metcalfe DH. Referral to hospital: can we do better? BMF 1988;297:461-4.

9 Young DW, Parkes J, Davis WA, Harman D, Williams RS. Out-patien letters: requirements and contents. Effective Health Care 1985;2:225-8.

10 Kentish R, Jenkins P, Lask B. Study of written communication between general practitioners and departments of child psychiatry. $\mathcal{F} R$ Coll Gen Prac 1987;37:162-3.

11 Scaffardi RA. Study of written communication between general practitioner and a community physiotherapist. $\mathcal{F} R$ Coll Gen Pract 1989;39:375-6.

(Accepted 20 December 1991)

\section{A PATIENT WHO CHANGED MY PRACTICE}

\section{Beware the repeat prescription}

As was common on a Saturday afternoon in Liverpool all the main roads to the city centre were devoid of traffic, making the house call I was engaged on that much easier to reach. It was to a friend's public house. His aged mother had been sick for several days.

Ray, the proprietor, ushered me into his mother's bedroom and "left me to it," as he descended to catch the football at Anfield, a mile or so away.

I asked, "What's the matter Mrs Smith?" as I sat on the edge of the bed.

"Don't know Doctor. Seeing funny things and feeling sick. It's been happening for a few days now." She retched slightly.

I examined her and couldn't find anything to account for the problems.

"Mrs Smith, are you on any tablets?"

"Yes, been taking thyroxine for many years. Me doctor in Walton Hospital says I've got a low thyroid gland. See. There."
I picked up the tablets. They were labelled digoxin $0 \cdot 25 \mathrm{mg}$ daily.

I left the room to ring the nearby hospital, thinking of medical school and the fascination in learning that digoxin overdose causes the periphery of vision to become blurred green and yellow.

Mrs Smith's notes were located. Her hypothyroidism and thyroxine $0.25 \mathrm{mg}$ daily was confirmed. After several days discontinuance of the digoxin the patient had improved sufficiently to admonish personally her general practitioner for the mistake. This was an example of repeat prescription signed but unchecked by the doctor.

How this patient changed my practice is simple. Whenever I write a prescription it is always in my own hand and the medication is generically recorded in block capitals with the actual units similarly noted.

Thus: DIGOXIN 25 MICROGRAMS PER DAY.-MAURICE WOOLDRIDGE is a consultant paediatrician in Tabuk, Saudi Arabia 